\title{
Preparation and impact properties of ES-U3160/5284 composites by RTM
}

\section{process}

\author{
Li Yan ${ }^{1,}$, Xuefeng $A n^{1, b}$ \\ ${ }^{1}$ National Key Laboratory of Advanced Composites, Beijing Institute of Aeronautical Materials, \\ AVIC Composite Technology Center, Beijing 100095, China \\ ayanli0827@163.com, banxuefeng@gmail.com,
}

\begin{abstract}
Keywords: polyethersulphone; Ex-situ toughening; low-velocity impact damage; ES-U3160 Fabrics Abstract. The ES-U3160 reinforced fabrics with toughening function were prepared by carrying the Ex-situ elasticizer polyethersulphone homogeneously on reinforced fabrics according to Ex-situ toughening technology. ES-U3160/5284 CF reinforced epoxy resin matrix composites were prepared by RTM process taking ES-U3160 fabrics as reinforcement. The effect of polyethersulphone on the impact properties of ES-U3160/5284 composites was investigated through low-velocity impact and SEM tests. The results showed that ES-U3160 fabrics were prepared by coating equipment independently developed, which realized preparation of the high quality, high efficiency and stabilization for ES-U3160 fabrics. CAI value of ES-U3160/5284 composites toughened by polyethersulphone increased by 55\%, compared with that of U3160/5284 non toughening composites, and the impact resistance ability of composites was improved effectively. Due to the addition of polyethersulphone, the phase version of polyethersulphone and 5284 epoxy resin occurred in the interplay of composites. This structure improved the damage resistance and damage tolerance of composites, which was the main reason improving the toughness of composites dramatically.
\end{abstract}

\section{Introduction}

Continues and intensive research and development on structural carbon fiber(CF) composites have led to the success that the latest aircraft like B787 is manufactured largely using these materials in the airframe structures. CF reinforced epoxy resin matrix composites have been used in the aerospace industry owing to their excellent properties such as ultra lightweight, high specific strength, high specific modulus, and high durability [1-3]. Although CF reinforced composites exhibit excellent in-plane properties, they typically show poor out-of-plane performance such as low resistance delamination, and this poor performance is primarily responsible for the low design strain for aircraft applications [4]. Improving toughness of composites has been always a focus of domestic and foreign concern.

The Resin Transfer Molding RTM process has been widely used in various industries because products can be manufactured easily and the cost for manufacturing is lower than that of other manufacturing methods [5-7]. But it's a great challenge for RTM technology to keep the processing while improving toughness of composites. Traditional toughness method was to blend thermoplastics into a matrix resin by dispersion or dissolving, but the integral toughness method had greatly increased viscosity of resin and decreased flow of resin, seriously affected RTM processing. However, Ex-situ tougheningtechnology [8-13] proposed by Xiaosu Yi can effectively solve the contradiction between low viscosity of resin and high toughness of composites during RTM process and significantly improve interlayer performance.

In this article, the ES-U3160 reinforced fabrics with toughening function were prepared by adhering the Ex-situ elasticizer polyethersulphone (PES) homogeneously on reinforced fabrics according to Ex-situ toughening technology. ES-U3160/5284 CF reinforced epoxy resin matrix composites were prepared by RTM process taking ES- Fabric reinforced fabrics as reinforcement. The preparation methods of ES-U3160 fabrics and their composites were studied and the impact properties of ES-U3160/5284 composites were compared with U3160/5284 nontoughening composites. 


\section{Materials and experimental method}

Epoxy resin(5284) is a product of Beijing Institute of Aeronautical Materials (BIAM), which is an aerospace-grade epoxy commercialized. U3160 unidirectional textile with an areal density of $160 \mathrm{~g} / \mathrm{m}^{2}$ was purchased from Weihai development Fiber Co., Ltd. Polyethersulphone (PES) with the model of VW-10200RFP was purchased from American Solvay company.

The quasi-isotropic composites with fiber reinforcement at [45/0/-45/90]4s were prepared. Composite laminates whose fiber volume fraction was $56 \% \pm 2 \%$ were molded according to the process requirement by resin transfer molding (RTM). Rectangular specimens cut from the laminates with in-plane size of $150 \mathrm{~mm} \times 100 \mathrm{~mm}$ were used to test.

The impact testing was performed using a drop-weight impact tester (INSTRON 9250HV). The drop-weight testing machine consists of a drop tower equipped with an impactor, which has high bandwidth digital signal processing (DSP) electronics, Impulse TM control and data acquisition software. After impact tests, all the specimens were subjected to compression strength testing to determine their compression-after-impact (CAI) characteristics and strength. Interlayer morphology of toughening composite laminates were observed by SEM.

\section{Results and discussion}

Preparation of ES-U3160 reinforced fabrics. The carrying amount of the thermoplastic toughening particle on ES-U3160 fabrics was set according to the thermoplastic toughening particle accounted for $10 \%$ to $15 \%$ of the matrix weight for the RTM composites and the optimal toughening effect was obtained. Fig. 1 showed the preparation course of ES-U3160 fabrics. ES-U3160 fabrics were prepared by coating equipment independently developed, which realized the preparation of high quality, high efficiency and stabilization for ES-U3160 fabrics. Fig. 2 showed the surface morphology of PES on the carbon fiber fabrics.

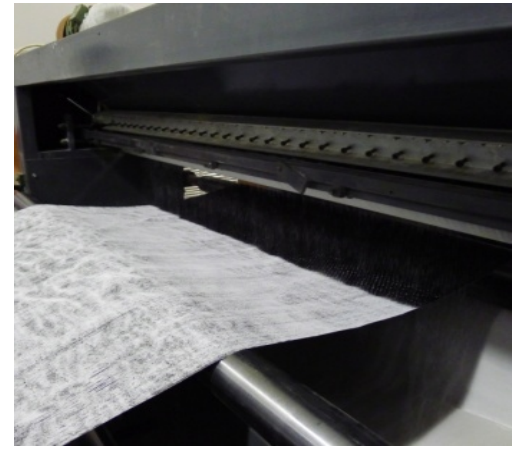

(a) PES dispersing in fabrics

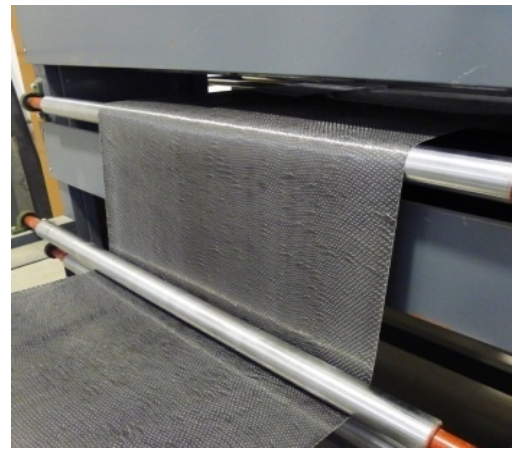

(b) Heating fixation

Fig.1 The preparation course of ES-U3160 composites

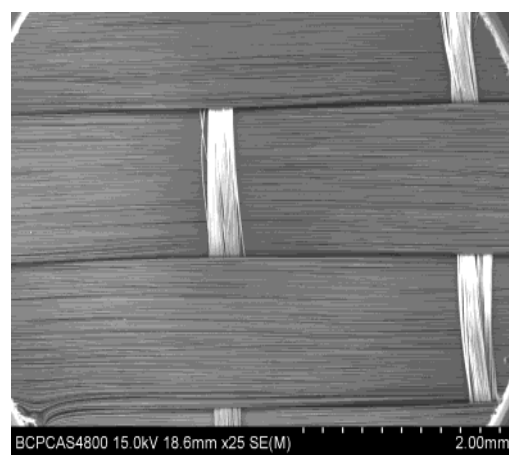

(a) U3610

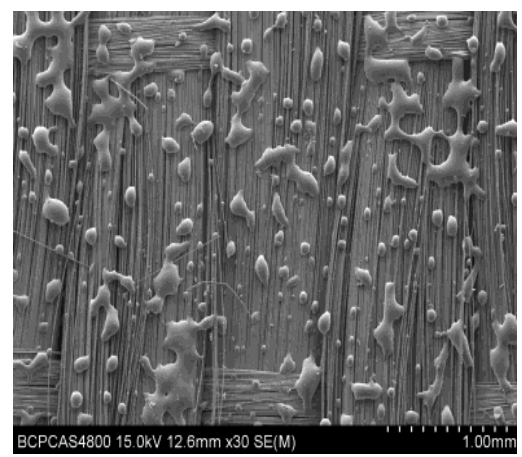

(b) ES-U3160

Fig. 2 SEM images of different fabrics 
Low velocity impact of ES-U3160/5284 composite laminates. Fig. 3 showed impact force histories for composites laminates. There were three meaningful force values related to the damage process as identified by various researchers. The load increased until a sudden drop occurs (at point $\mathrm{A}$ of the curve). The load at point A was defined as the critical force for onset of delamination, Fcr. This delamination process was accompanied by a rapid reduction of the force to the rest value Fr (point B) due to reduction in the transverse stiffness of the laminate. A reloading phase of the specimen to a maximum point Fmax (point $\mathrm{C}$ ) may occur if enough residual potential energy was stored in the impactor. In fact Fmax was also related to the target plate stiffness the initial impact damage at Fcr. From the graph, we could conclude that the delamination onset load and the maximum load of ES-U3160/5284 toughening composites were higher than U3160/5284 non toughening composites. This is due to the plastic deformation of interlayer elasticizer which improved impact resistance ability .

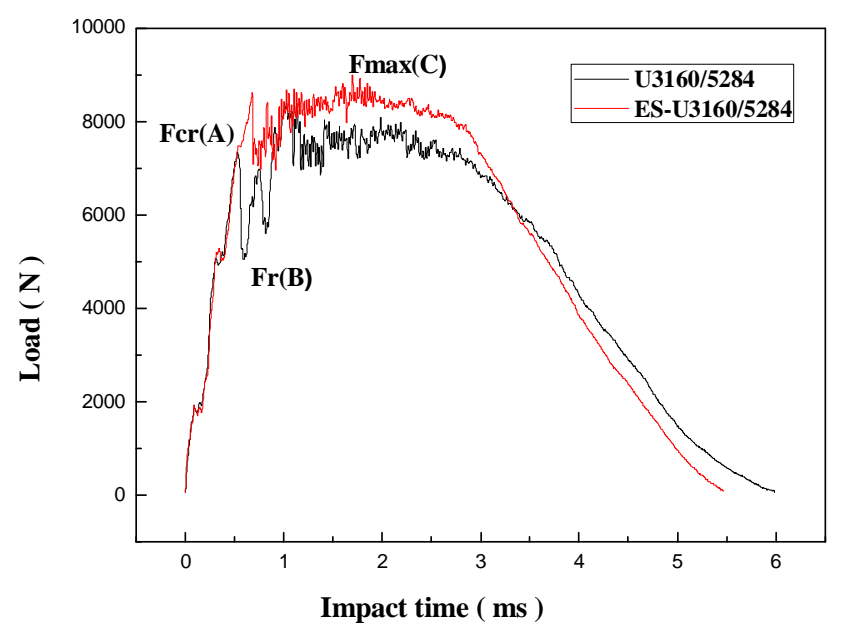

Fig. 3 Impact force histories for composites laminates

As seen from Fig. 4, the large area of delamination damage occurred in the $0{ }^{\circ}$ overlay interface of U3160/5284 non toughening composites, and the damage is very serious. A severe layer inside the crack is occurred below the impact part and several layers of the rupture happened on the back. The damage of the ES-U3160/5284 toughening composites was greatly relieved compared with U3160/5284 non toughening composites.
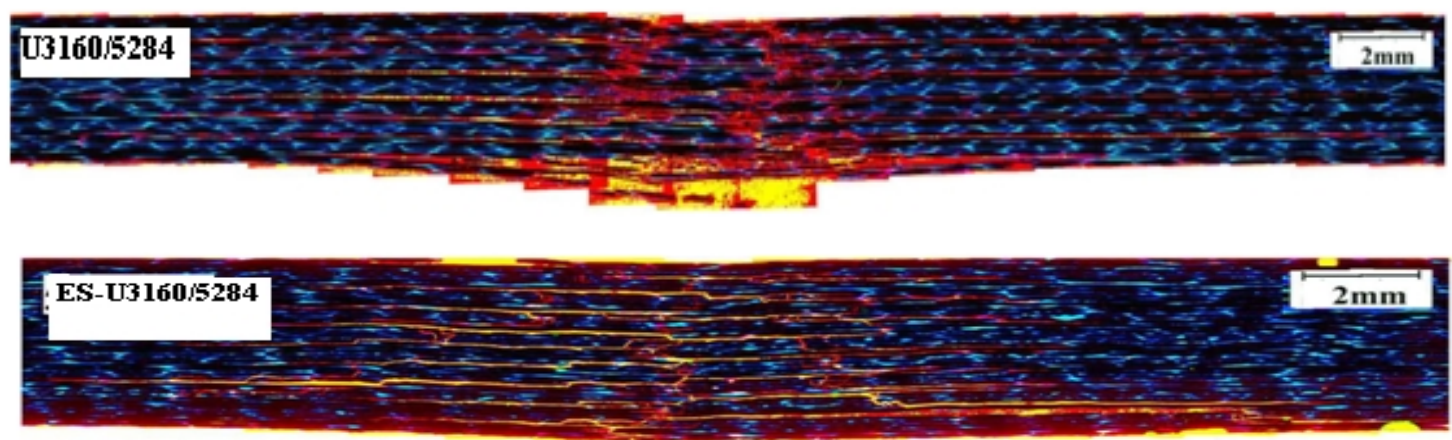

Fig.4 The fluorescent optical microscopy of cross sections for 5284 epoxy matrix composites after impact

As shown in Fig. 5, CAI value of ES-U3160/5284 composites toughened by polyethersulphone increased by $55 \%$, compared with that of non tougheningcomposites. The toughened laminates were damaged after impact. As seen from C-scan, the damage area of the ES-U3160/5284 toughening laminate is that of the U3160/5284 non toughening laminate 1/6. Ex-situ toughening can inhibit the internal damage extension of ES-U3160/5284 composite laminates. 


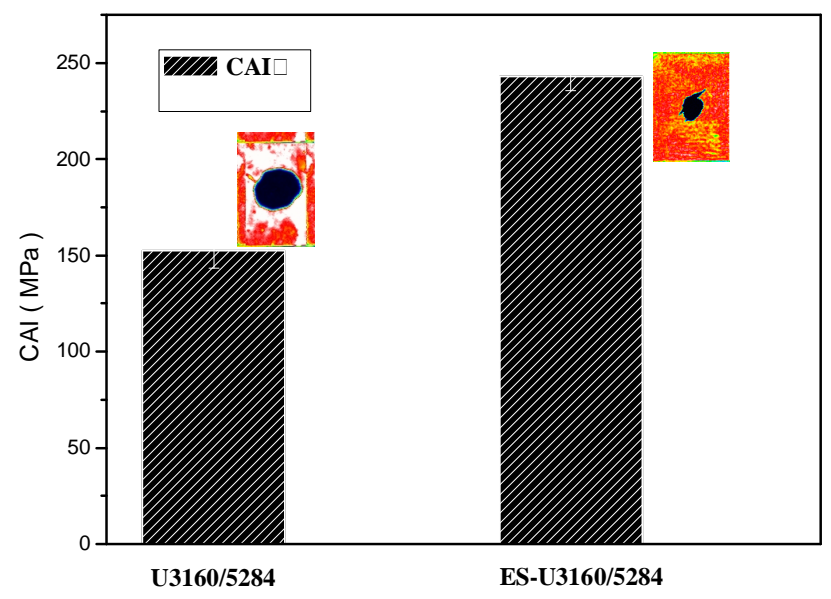

Fig. 5 The CAI value and C-scan photos of 5284 epoxy matrix composites
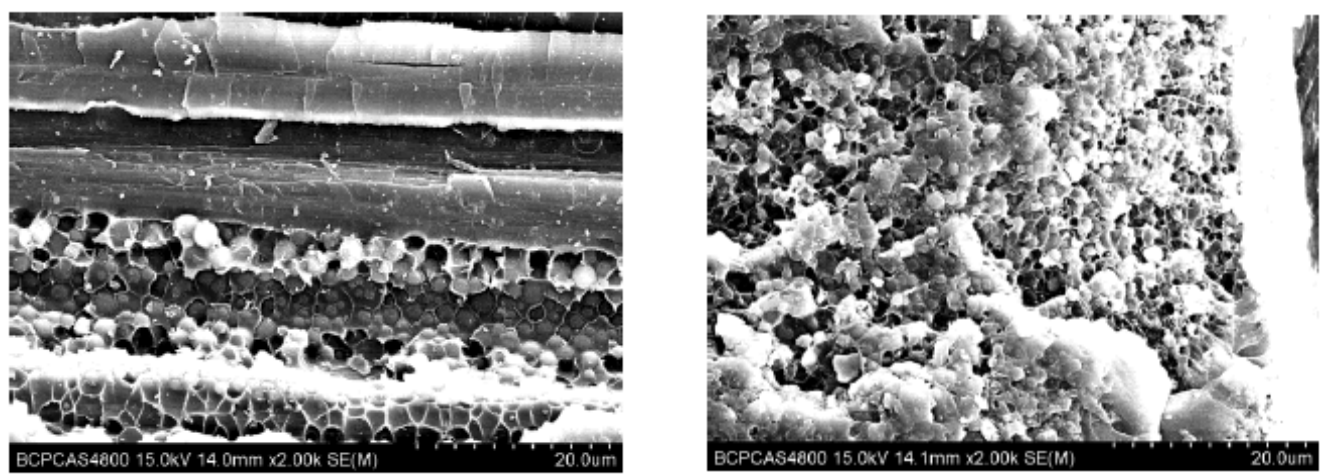

Fig. 6 SEM morphology of ES-U3160/5284 composites toughened by polyethersulp Interlayer morphology analysis of ES-U3160/5284 composite laminates. The thermoplastic PES was etched and removed from the specimen of ES-U3160/5284. The SEM morphology of ES-U3160/5284 composites toughened by polyethersulphone was shown in Fig. 6. As seen from Fig. 6, the thermoplastic PES between the interlayer toughened specimen had not exist, and the rest was epxoy spherical particles. It was illustrated that the phase inversion structure was appeared in the interlayer. The thermal plastic PES was the continuous phase while the 5284 epoxy resin was the dispersed phase. The structure and the typical Ex-situ toughening epoxy resin matrix composites with the two phase structures of the laminates [14] were in good agreement. The inversion structure of the layer was the reason for the remarkable increase of the compression strength after impact. This was the essence of Ex-situ toughening technology that the high toughness thermoplastic resin was limited to the weakest level in the composites. Because the thermoplastic elasticizer had good toughness and plastic deformation ability, plastic deformation would be significantly absorbed energy and inhibit the hierarchical expansion when subjected to impact. So under the same impact energy, The toughening laminates had not only small damage area, but also the compression strength of the laminates were significantly improved than the non toughening laminates.

\section{Conclusions}

Following conclusions were drawn from this work:

(1) ES-U3160 fabrics were prepared by coating equipment independently developed, which realized the preparation of high quality, high efficiency and stabilization for ES-U3160 fabrics.

(2) The CAI value of ES-U3160/5284 composites toughened by polyethersulphone increased by $55 \%$, compared with that of non toughening composites, and the impact resistance ability of composites was improved effectively. 
(3) Due to the addition of polyethersulphone, the phase version of polyethersulphone and 5284 resin occurred in the interplay of composites. This structure improved the damage resistance and damage tolerance of composites, which was the main reason improving the toughness of composites dramatically.

\section{References}

[1] Roeseler WG, Sarh B, Kismarton MU. Composite structures: the first 100 years [C]. In 16th International Conference on Composite Materials. Kyoto, July, 2007.

[2] Botelhoa EC, Figiel L, Rezende MC, et al. Evaluation of fatigue behavior on repaired carbon fiber/epoxy composites [J]. Compos Sci Technol, 2003, 63: 1843-55.

[3] Soutis C. Interlaminar fracture toughness of nylon 66 nanofibrilmat interleaved carbon/epoxy laminates [J]. Polym Comp, 2011, 32: 1781-1789.

[4] Bradley WL, Cohen RN. Matrix deformation and fracture in graphite-reinforced epoxies [J]. Philadelphia (PA): ASTM STP 876, 1985: 389-410.

[5] Kim PJ, Lee DG. Surface quality and shrinkage of the composite bus housing panel manufactured by RTM [J]. Compos Struc, 2002, 57: 211-20.

[6] Mallick PK. Proceedings of the twelfth US-Japan conference on composite materials [C]. USA: DEStech Publications, 2006.

[7] Lee GW, Lee NG, Janga J, Lee KJ, Nam JD. Effects of surface modification on the resin-transfer moulding (RTM) of glass-fibre/unsaturated-polyester composites. Compos Sci Technol, 2002, 62: 9-16.

[8] X F An, B M Tang, X S Yi, et a1. Toughness improvement of carbon laminates by periodic interleaving thin films [J]. Journal of Materials Science Letters, 2002, 21(22): 1763-1765.

[9] X S Yi, X F An, B M Tang, et a1. Ex-situ formation of periodic interlayer structure to improve significantly the impact damage resistance of carbon laminates [J]. Advance Engineering Materials, 2003, 5(10): 729-732.

[10] Long W, Xu Y H, Yi X S, et al. Preliminary study on resin transfer molding of highly-toughened graphite laminates by Ex-situ method [J]. Journal of Materials Science, 2004, 39(6): 2263-2266.

[11] Q F Cheng, Z P Fang, Y H Xu, et al. Improvement of the impact damage resistance of BMI/graphite laminates by the Ex-situ method [J]. High Performance Polymers, 2006, 18(6): 907-917

[12] Q F Cheng, Z P Fang, X S Yi, et al. Ex-situ concept for toughening the RTM able BMI matrix composites I: Improving the interlaminar fracture toughness [J]. Journal of Applied Polymer Science, 2008, 109(3): 1625-1634.

[13] Q F Cheng, Z P Fang, Y H Xu, et al. Morphological and spatial effects on toughness and impact damage resistance of PAEK-toughened BMI and graphite fiber composite laminates [J], Chinese Journal of Aeronautics, 2009, 22(1): 87-96 .

[14] INOUE T. Reaction-induced in phase decomposition in polymer blends [J]. Progress in polymer science, 1995, 20: 119-153. 